Научная статья

УДК 519.68:15:681.5

DOI https://doi.org/10.24866/VVSU/2073-3984/2021-3/132-146

В.М. Гриняк

Владивостокский государственный университет экономики и сервиса Владивосток. Россия

\title{
Планирование схемы безопасного движения на морской акватории
}

\begin{abstract}
Статья посвящена проблеме обеспечения безопасности движения судов на морских акваториях. В условиях насыщенного трафика навигационная безопасность может быть обеспечена только при соблюдении судами определённой схемы движения. В работе ставится задача планирования системы маршрутов (схемы движения) судов через акватории с интенсивным трафиком. Эта схема зависит от географии акватории и особенностей трафика. Выбор того или иного варианта схемы обусловлен необходимостью обеспечения максимальной безопасности движения и практическими соображениями. Особенности задачи затрудняют её прямое решение традиционными методами и средствами, так как они приводят к алгоритмам высокой вычислительной сложности. Так, модельное представление задачи на основе взвешенного графа не позволяет решить ее без привлечения специализированных вычислительных ресурсов. Предложен альтернативный подход: конструирование схем движения экспертным способом из типичных структурных элементов (примитивов) и моделирование движения судов по множеству возможных траекторий с оценкой метрики, описывающей степень опасности движения. В качестве метрики опасности предлагается частота опасных сближений судов, отмечается возможность использования и других метрик. Имитационное моделирование задачи изолировано в рамках отдельного примитива вполне возможно на доступных вычислительных и программных платформах общего назначения. В работе рассмотрены четыре таких примитива, оценено среднее время между опасными сближениями судов для каждого из них. Приведён пример использования полученных результатов моделирования для планирования безопасных схем движения судов.
\end{abstract}

Ключевые слова и словосочетания: безопасность судоходства, управление движением судов, система установления путей движения, интенсивное движение, опасное сближение, моделирование судопотока, алгоритмы на графах.

Гриняк Виктор Михайлович - д-р техн. наук, профессор кафедры информационных технологий и систем; e-mail: Viktor.Grinyak@ vvsu.ru

132 
V.M. Grinyak

Vladivostok State University of Economics and Service

Vladivostok. Russia

\section{Planning of safe traffic schema for marine area}

This work is devoted to the problem of ensuring the safety of vessel traffic at marine areas. Navigation safety in conditions of heavy traffic can be ensured only if the vessels comply with a certain traffic pattern. The paper highlights the problem of planning a system of routes (traffic patterns) of vessels through water areas with heavy traffic. This schema depends on the geography of the water area and the characteristics of traffic. The necessity to ensure the maximum safety of vessel traffic and practical considerations determine the choice of a specific variant for a traffic scheme. Modeling the vessels motion along a set of possible trajectories and evaluating the metric describing the degree of movement danger is the basis of the method for solving the problem. The frequency of dangerous approaches of vessels is proposed as a metric for assessing the danger of traffic, and the possibility of using other metrics is noted. The work demonstrates that the model representation of the problem based on a weighted graph does not allow its solution with-out the involvement of specialized computing resources. An alternative approach is motion construction of schemes in an expert way from typical structural elements (primitives). Simulation modeling of a problem becomes possible on available general-purpose computing and software platforms if it is isolated within a separate primitive. The paper considers four such primitives and estimates the average time between dangerous approaches of vessels for each of them. An example of using the obtained modeling results for planning safe ship traffic patterns is given.

Keywords: maritime safety, marine traffic control, traffic pattern, traffic intensity, collision risk assessment, ships flow simulation modeling, graph algorithms.

\section{Введение}

Традиционным подходом к обеспечению навигационной безопасности движения судов является решение трёх задач: оценка риска опасного сближения, предупреждение опасного сближения и планирование траектории безопасного движения судов [22]. На акваториях с интенсивным трафиком эти классические задачи не всегда способны обеспечить необходимый уровень безопасности, в связи с чем необходима дополнительная координация совместных действий участников движения, в том числе - в форме следования определенной на акватории схеме безопасного движения (правилам движения) [2; 11]. В судоводительской практике в отношении такой схемы устоялся термин «система установления путей движения судов» $[12 ; 13]$.

Исторически формирование схемы движения конкретной акватории происходило исходя из возможности её реализации с учетом географии района и судоводительской практики. Важным было наличие удобных визуальных ориентиров, позволяющих судоводителю следовать установленным маршрутом [10; 18; 19]. При необходимости естественные ориентиры (приметные горы, мысы, острова и т.п.) дополнялись искусственными (маяки, светящиеся знаки, буи и т.п.). Соотнесенный 
с правилами судовождения такой подход приводил к формированию схемы движения не столько безопасной, сколько удобной для повседневной работы судоводителей и диспетчеров береговых служб в условиях ограниченных возможностей навигационных средств прошлых лет (до наступления цифровой эпохи).

Рост интенсивности судоходства в последние годы нередко выявлял ограничения «старых» схем с точки зрения их пропускной способности и безопасности $[3 ; 5 ; 8]$. Одновременно с этим развитие концепции Е-навигации и приход нового поколения навигационных средств (спутниковые системы позиционирования, системы автоматизированной прокладки, Автоматическая идентификационная система) $[1 ; 15 ; 21]$ позволили реализовать любые допустимые географией акватории маршруты судов, не ограничиваясь возможностями визуального наблюдения $[14 ; 16 ; 17]$. Это определило необходимость и перспективность разработки новых подходов к планированию схем движения судов на морских акваториях.

Настоящая работа посвящена исследованию задачи планирования схемы движения судов, обеспечивающей безопасность в условиях высокой интенсивности трафика. В основу метода решения задачи положены имитационное моделирование движения по множеству возможных траекторий и оценка метрики, описывающей степень опасности движения. Выбор в пользу того или иного варианта схемы движения из возможных определен необходимостью обеспечения максимальной безопасности коллективного движения и практическими соображениями. Актуальность исследования обусловлена, в том числе, перспективами развития безэкипажного судоходства [4; 20].

\section{Основные модельные представления}

Пусть имеется некоторая акватория, на которой выделены разрешенные и запрещённые для движения судов районы. Имея в виду небольшие размеры типичных акваторий (обычно не более 100 км, можно пренебречь шарообразностью Земли), для их моделирования будем использовать прямоугольную декартову систему координат.

Примем, что на границах и внутри акватории имеются зоны входа судов на акваторию $I N_{m}(m=\overline{1, M})$ и зоны выхода судов с акватории $O U T_{n}(n=\overline{1, N})$. Зоны могут быть как непересекающимися, так и пересекающимися. Будем считать известной интенсивность судопотока $A_{m n}$ из зоны $I N_{m}$ в зону $O U T_{n}$, выражаемую, например, количеством выходящих судов в единицу времени при заданных характерных скоростях, геометрических размерах и траекторных свойствах судов. Такое представление позволяет моделировать потоки судов, проходящих через акваторию [12; 13].

Пусть заданы маршруты судов из зон входа в зоны выхода. Будем осуществлять моделирование трафика акватории в дискретные моменты времени $t_{i}$. Moдель движения конкретного судна опишем кинематическими уравнениями:

$$
\begin{aligned}
& x_{i+1}=x_{i}+v_{i} \sin K_{i}\left(t_{i+1}-t_{i}\right), \\
& y_{i+1}=y_{i}+v_{i} \cos K_{i}\left(t_{i+1}-t_{i}\right),
\end{aligned}
$$

где $x_{i}, y_{i}$,- декартовы координаты судна в момент времени $t_{i}, v_{i}, K_{i}$ - соответственно скорость и курс судна. 
Примем, что модель скорости и курса судна включают в себя случайную компоненту, так что $v_{i+1}=v i+\delta v_{i}$ (где $\delta v_{i}$ - случайная величина с известным распределением), а курс судна $K_{i}$ выбирается на каждом шаге так, чтобы обеспечивать движение по заданному маршруту, так что $K_{i}+K_{i}^{*}+\delta K_{i}$ (где $K_{i}^{*}-$ определяемое траекторией значение курса судна, $\delta K_{i}-$ случайная величина с известным распределением).

Будем генерировать суда в зонах $I N_{m}$ согласно заданной интенсивности судопотока $A_{m n}$ и моделировать движение судов к зонам $O U T_{n}$, по мере их достижения удаляя суда из обработки. Тем самым получим имитационную модель движения судов на акватории.

В качестве метрики, характеризующей степень опасности движения, выберем количество опасных сближений судов в единицу времени [8]. Будем считать взаимное расположение судов опасным, если расстояние между ними меньше некоторого критического расстояния $R^{*}$, зависящего от геометрических размеров судов. Реализуя имитационную модель движения судов, можно вести подсчет опасных сближений судов как на всей акватории, так и на её отдельных участках, выявляя тем самым наиболее проблемные.

Таким образом, ставится задача выбора множества маршрутов судов из зон входа $I N_{m}$ в зоны выхода $O U T_{n}$ так, чтобы они обеспечивали минимум количества опасных сближений судов в рамках описанной имитационной модели. Решение этой задачи позволит спланировать схему безопасного движения на выбранной акватории.

Рассмотрим модель поставленной задачи на графе. Пусть на акватории определено множество рёбер и множество вершин. Множество вершин графа формируется в виде равномерной квадратной сетки с заданным расстоянием между вершинами. Множество ребер задается так, чтобы каждая вершина была соединена отрезком с другой. Чтобы число ребер не было чрезмерным, их возможная длина ограничивается. Учитывается география акватории: нет вершин в запрещённых для плавания районах, ребра не должны пересекать такие районы.

Вершины, расположенные в зонах $I N_{m}$ и $O U T_{n}$, являются начальными и конечными точками возможных маршрутов судов. Пусть $P_{m n}-$ множество возможных путей на графе, приводящих из зоны $I N_{m}$ в зону $O U T_{n}$. Для уменьшения числа возможных путей целесообразно ввести ряд ограничений: на длину пути, на величину изменения курса судна в вершине, запретить циклические пути и т.п. Моделируя движение по возможным путям, получим количество опасных сближений судов для каждой пары путей. Решение исходной задачи планирования схемы движения дают те пути, которые обеспечивают минимум опасных сближений.

Выбор путей из множеств $P_{m n}$ приводит (в случае реальных акваторий) к необходимости имитационного моделирования задачи для очень большого числа судов. Ещё одной проблемой, возникающей при решении описанной задачи, является случайный характер оценки количества опасных сближений для пар выбранных путей. Это не даёт возможность устойчиво различить похожие пути с точки зрения меры их безопасности: разные реализации модели дают существенно различающиеся оценки маршрутов схемы движения судов. Уменьшить 
случайную составляющую в оценке количества опасных сближений возможно, если на несколько порядков увеличить число моделируемых судов, однако это потребует использования специализированных вычислительных ресурсов. Другими словами, особенности описанной задачи затрудняют её прямое решение для акватории в целом традиционными методами и средствами.

Альтернативным подходом является конструирование возможных схем движения экспертным способом из структурных элементов (примитивов), представляющих собой принятые в практике судовождения типичные конфигурации траекторий. Реализация описанной имитационной модели изолированно в рамках отдельного примитива вполне возможна на доступных вычислительных и программных платформах общего назначения.

Рассмотрим следующие примитивы траекторий судов:

- пересечение односторонних судопотоков одинаковой интенсивности (рис. 1a);

- пересечение двусторонних судопотоков одинаковой интенсивности (рис. 1б);

- пересечение двусторонних судопотоков разной интенсивности (рис. 1в);

- пересечение двусторонних судопотоков с зоной кругового движения (рис. 1г).
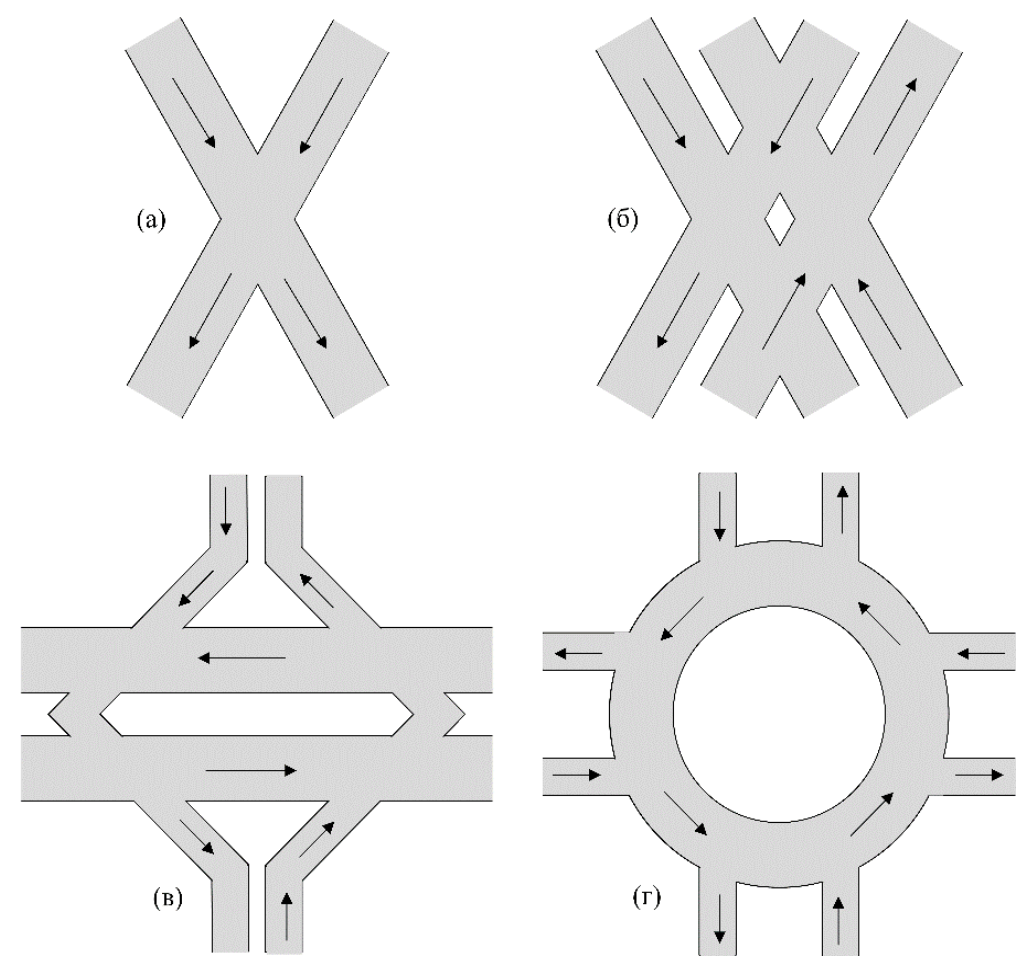

Рис. 1. Модели примитивов траекторий судов

В первом случае (см. рис. 1а) считается, что односторонние судопотоки равной интенсивности пересекаются под некоторым углом (интенсивность судопо- 
тока выражается в количестве судов, проходящих за единицу времени при заданной скорости). Требуется оценить характерное количество опасных сближений в зависимости от угла пересечения судопотоков, их интенсивности и размеров судов (значений параметра $R^{*}$ ).

Во втором случае (см. рис. 1б) считается, что двусторонние судопотоки равной интенсивности пересекаются под некоторым углом. Эта ситуация соответствует «суммированию» четырёх примитивов, показанных на рисунке 1а. Здесь тоже нужно оценить характерное количество опасных сближений в зависимости от угла пересечения судопотоков, их интенсивности и размеров судов.

В третьем случае (см. рис. 1в) считается, что двусторонний судопоток большой интенсивности пересекается двусторонним судопотоком менышей интенсивности. Суда, движущиеся в «большом» судопотоке, сохраняют прямолинейное движение, а суда, движущиеся в «малом» судопотоке, изменяют курс для пересечения «большого» судопотока под возможно меньшим углом. Требуется оценить характерное количество опасных сближений в зависимости от угла пересечения судопотоков, размеров судов, интенсивности потоков судов и их скоростей.

В четвертом случае (см. рис. 1г) считается, что пересекаются двусторонние судопотоки с одинаковой интенсивностью движения, а для уменьшения числа опасных сближений организовано круговое движение. Требуется оценить характерное количество опасных сближений в зависимости от размеров судов и интенсивности их потоков.

\section{Результаты}

Рассмотрим пересечение односторонних судопотоков одинаковой интенсивности (см. рис. 1a). На рисунке 2 показаны результаты оценки среднего количества опасных сближений судов: по оси абсцисс отложен угол пересечения судопотоков $\gamma$ (в градусах), по оси ординат - средний период между опасными сближениями $\tau$ (в минутах). При этом были приняты следующие значения параметров (табл. 1): $R^{*}$ равно 300, 600 и 900 метров, временные интервалы между соседними судами, движущимися в потоке, являются случайными значениями и равномерно распределены в отрезке $[1,10]$ и $[1,20]$ минут, скорость судов составляла 10 м/с. Здесь и в следующих примерах моделирование движения судов проводилось на интервале 100 дней.

Таблица 1

\section{Параметры судопотоков (односторонних одинаковой интенсивности)}

\begin{tabular}{|c|c|c|}
\hline Номер графика & Расстояние между судами $R^{*}$, м & Интервал времени между судами, мин \\
\hline 1 & 300 & {$[1,20]$} \\
\hline 2 & 600 & {$[1,20]$} \\
\hline 3 & 900 & {$[1,20]$} \\
\hline 4 & 300 & {$[1,10]$} \\
\hline 5 & 600 & {$[1,10]$} \\
\hline 6 & 900 & {$[1,10]$} \\
\hline
\end{tabular}




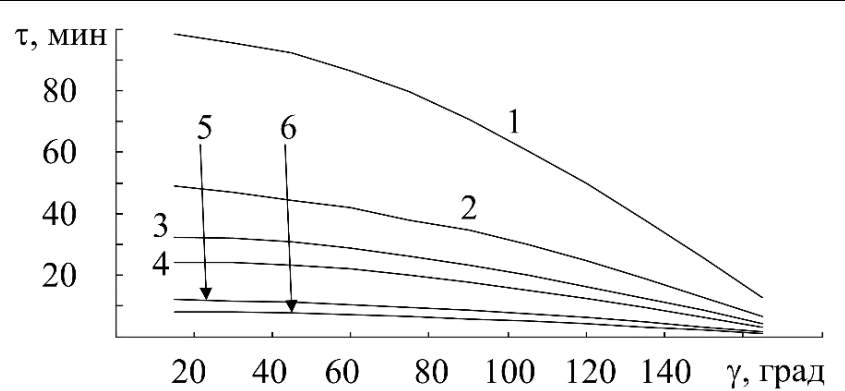

Рис. 2. Средний интервал между опасными сближениями: пересечение односторонних судопотоков одинаковой интенсивности

Из рисунка 2 видно, что имеет место близкая к обратной линейной зависимость средних интервалов между опасными сближениями $\tau$ от критического расстояния между судами $R^{*}$ (это хорошо видно, например, при сопоставлении графиков 1 и 2, 4 и 5). Близкая к квадратичной зависимость наблюдается между длиной интервала времени между соседними судами и $\tau$. Последнее легко предположить априорно, так как при уменьшении интервала времени между судами обратно пропорционально увеличивается число судов в каждом судопотоке. Видно также, что при пересечении судопотоков под острым углом величина $\tau$ в несколько раз выше, чем при пересечении под «очень тупыми» углами (больших, чем $135^{\circ}$ ); разница в величине $\tau$ для «очень острых» углов (меньших, чем $45^{\circ}$ ) невелика (около 10\%). Таким образом, при планировании схемы движения следует стремиться к пересечению односторонних судопотоков только под острыми углами, однако уменьшение углов ниже $45^{\circ}$ уже не даёт существенного эффекта.

Пересечение двусторонних судопотоков (см. рис. 1б) сводится к комплексированию четырёх примитивов односторонних судопотоков. На рисунке 3 показаны результаты оценки среднего количества опасных сближений судов для случая двусторонних судопотоков одинаковой интенсивности и параметров движения, представленных в табл. 1; как и в предыдущем примере по оси абсцисс отложен угол пересечения судопотоков $\gamma$ (в градусах), по оси ординат средний период между опасными сближениями $\tau$ (в минутах).

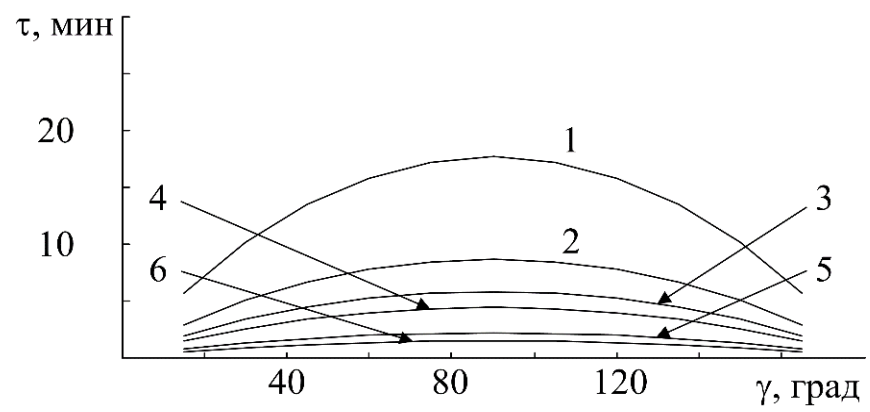

Рис. 3. Средний интервал между опасными сближениями: пересечение двусторонних судопотоков одинаковой интенсивности 
Из рисунка 3 видно, что, как и можно предположить, значения $\tau$ симметричны относительно угла $\gamma=90^{\circ}$; при таких значениях $\gamma$ значения $\tau$ в четыре раза меньше, чем на соответствующих графиках рис. 2. Так как в точке $\gamma=90^{\circ}$ достигается максимум значений $\tau$, при планировании схемы движения следует стремиться к пересечению двусторонних судопотоков под прямым углом.

Рассмотрим пересечение двусторонних судопотоков разной интенсивности (см. рис. 1в). На рисунке 4 показаны результаты оценки среднего количества опасных сближений судов, были приняты следующие значения параметров (см. табл. 2). Как и в двух примерах ранее, по оси абсцисс отложен угол пересечения судопотоков $\gamma$ (в градусах), по оси ординат - средний период между опасными сближениями $\tau$ (в минутах). Были приняты следующие значения параметров (см. табл. 2): $R^{*}$ равно 300, 600 и 900 метров, временные интервалы между соседними судами, движущимися в «большом» потоке, равномерно распределены в отрезке $[1,10]$ минут, в «малом» потоке - в отрезках $[1,20]$ и $[1,40]$ минут. Скорость судов в «большом» потоке составляла 10 м/с (сплошные линии) и 20 м/с (пунктир), скорость судов в малом потоке была равна 10 м/с.

Таблииа 2

\section{Параметры судопотоков (двусторонних разной интенсивности)}

\begin{tabular}{|c|c|c|c|c|c|}
\hline $\begin{array}{c}\text { Номер } \\
\text { графика }\end{array}$ & $\begin{array}{c}\text { Расстояние } \\
\text { между судами } \\
R^{*}, \text { м }\end{array}$ & $\begin{array}{c}\text { Интервал вре- } \\
\text { мени между } \\
\text { судами, боль- } \\
\text { шой поток, мин }\end{array}$ & $\begin{array}{c}\text { Интервал вре- } \\
\text { мени между } \\
\text { судами малый } \\
\text { поток, мин }\end{array}$ & $\begin{array}{c}\text { Скорость } \\
\text { судов, боль- } \\
\text { шой поток, } \\
\text { м/с }\end{array}$ & $\begin{array}{c}\text { Скорость } \\
\text { судов, } \\
\text { малый } \\
\text { поток, м/с }\end{array}$ \\
\hline 1 & 300 & {$[1,10]$} & {$[1,40]$} & 10 & 10 \\
\hline 2 & 300 & {$[1,10]$} & {$[1,40]$} & 20 & 10 \\
\hline 3 & 300 & {$[1,10]$} & {$[1,20]$} & 10 & 10 \\
\hline 4 & 300 & {$[1,10]$} & {$[1,20]$} & 20 & 10 \\
\hline 5 & 600 & {$[1,10]$} & {$[1,40]$} & 10 & 10 \\
\hline 6 & 600 & {$[1,10]$} & {$[1,40]$} & 20 & 10 \\
\hline 7 & 900 & {$[1,10]$} & {$[1,40]$} & 10 & 10 \\
\hline 8 & 900 & {$[1,10]$} & {$[1,40]$} & 20 & 10 \\
\hline 9 & 600 & {$[1,10]$} & {$[1,20]$} & 10 & 10 \\
\hline 10 & 600 & {$[1,10]$} & {$[1,20]$} & 20 & 10 \\
\hline 11 & 900 & {$[1,10]$} & {$[1,20]$} & 10 & 10 \\
\hline 12 & 900 & {$[1,10]$} & {$[1,20]$} & 20 & 10 \\
\hline
\end{tabular}




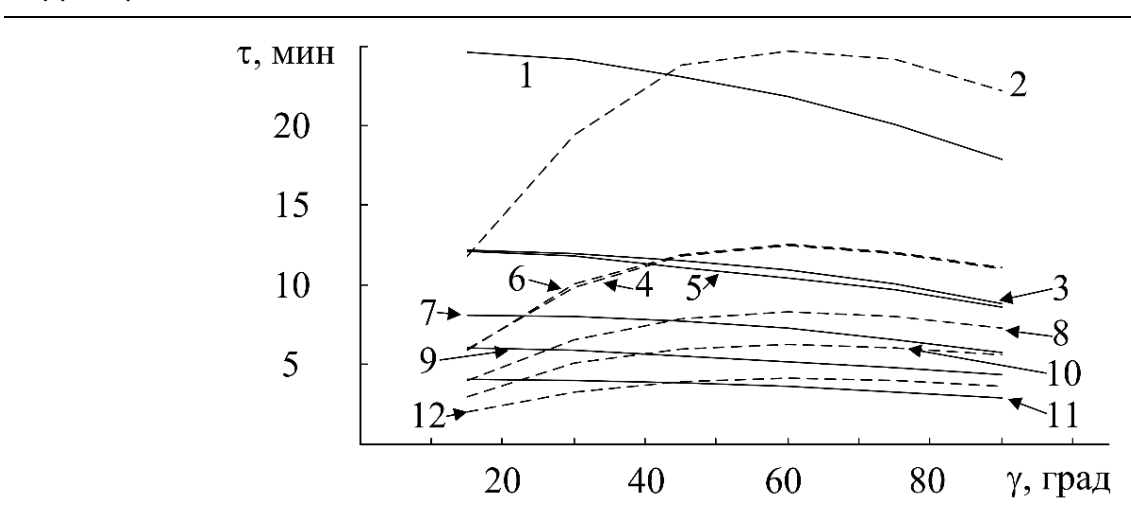

Рис. 4. Средний интервал между опасными сближениями: пересечение двусторонних судопотоков разной интенсивности

Из рисунка 4 следует, что имеется близкая к обратной линейной зависимость средних интервалов между опасными сближениями $\tau$ от критического расстояния между судами $R^{*}$. Близкая к линейной зависимость наблюдается также между $\tau$ и интервалом времени между соседними судами в «малом» потоке. Это создаёт, например, эффект очень близких (почти совпадающих) графиков 3 и 5, 4 и 6. В случае, если скорости судов в пересекающихся потоках не равны, величина $\tau$ при острых углах их пересечения резко уменьшается (пунктирные графики). Это объясняется тем, что суда «быстрого» потока догоняют суда «медленного» потока. В случае равных по скорости судопотоков наибольшие значения $\tau$ обеспечиваются при углах их пересечения меньше $45^{\circ}$, разница между ними в этом случае незначительна (не превышает 10\%). Таким образом, наиболее удобным для практики является пересечение судопотоков под углом в $45^{\circ}$ при близких скоростях движения судов.

Рассмотрим пересечение двусторонних судопотоков с зоной кругового движения (см. рис. 1г). В таблице 3 отражен результат оценки среднего периода между опасными сближениями судов. При моделировании для простоты считалось, что судопотоки имеют одинаковую интенсивность движения и движутся только в направлениях «верх-низ», «низ-верх», «право-лево», «лево-право», что определяет интенсивность движения «на круге». Все судопотоки были равной ширины, внутренний радиус «круга» был принят равным двум расстояниям между противоположными «прямыми» судопотоками.

Из таблицы 3 видно, что и в случае кругового движения имеется близкая к обратной линейной зависимость между $R^{*}$ и $\tau$; так же как и в примерах ранее, наблюдается близкая к квадратичной зависимость между $\tau$ и длиной интервала времени между соседними судами. Данные табл. 3 обосновывают преимущество круговой схемы при пересечении двусторонних судопотоков с интенсивным движением. Так, при $R^{*}=300$ м и случайном интервале времени между судами в отрезке $[1,20]$ (строка 1) значения $\tau$ для кругового движения (24.6 минут) примерно на треть выше, чем при пересечении двусторонних судопотоков под пря- 
мым углом (около 18 минут, максимум графика 1, рис. 3). Похожее соотношение можно увидеть и для судопотоков с другими параметрами.

Таблий 3

Параметры судопотоков (двусторонних с зоной кругового движения) и среднее количество опасных сближений судов

\begin{tabular}{|c|c|c|c|}
\hline № п/п & $\begin{array}{c}\text { Расстояние между су- } \\
\text { дами } R^{*}, \text { м }\end{array}$ & $\begin{array}{c}\text { Интервал времени } \\
\text { между судами, мин }\end{array}$ & $\begin{array}{c}\text { Средний период между опасными } \\
\text { сближениями } \tau, \text { мин }\end{array}$ \\
\hline 1 & 300 & {$[1,20]$} & 24.6 \\
\hline 2 & 600 & {$[1,20]$} & 12.3 \\
\hline 3 & 900 & {$[1,20]$} & 8.2 \\
\hline 4 & 300 & {$[1,10]$} & 6.0 \\
\hline 5 & 600 & {$[1,10]$} & 3.0 \\
\hline 6 & 900 & {$[1,10]$} & 2.0 \\
\hline
\end{tabular}

Результаты моделирования движения судов на примитивах дают представление о характерном количестве опасных сближений в том или ином случае. С учетом указанных зависимостей это количество может быть экстраполировано на судопотоки с другими параметрами. Значение $\tau$ - среднее время, которое проходит между опасными сближениями судов на небольшом участке акватории. С учетом типичного времени реагирования судоводителей и ответственных за участок операторов береговых СУДС на предупреждение о риске опасного сближения и на принятие решения и совершение маневра уклонения значения $\tau$ менее 10 минут следует считать нежелательными, а менее 5 минут - опасными [8]. Например, при $R^{*}=300$ м для односторонних судопотоков движение безопасно при острых углах их пересечения при длине интервала времени между судами как $[1,20]$, так и $[1,10]$ минут. При пересечении двусторонних судопотоков одинаковой интенсивности движение судов с интервалом $[1,20]$ безопасно (рис. 3, график 1), а с интервалом [1,10] опасно (см. рис. 3, график 4). Это даёт представление о пропускной способности данного примитива траекторий судов. При движении, как на рис. 1в, движение с указанными интервалами безопасно. При движении, как на рис. 1г, интервал $[1,20]$ безопасен, интервал $[1,10]$ тоже безопасен (в отличие от примитива рис. 1б), хотя и находится вблизи опасной зоны. Сравнение рис. 4 и табл. 3 даёт представление о необходимости организации кругового движения при тех или иных параметрах судопотоков.

Кроме количества опасных сближений возможны и другие метрики опасности движения. Так, в работе [9] рассматриваются метрики «интенсивность движения», «интенсивность плюс скорость движения», «интенсивность плюс размеры судов». Первая характеризует количество судов, проходящих через некоторый участок акватории за единицу времени. Вторая аналогична первой метрике, но судам соответствует «вес», зависящий скорости движения, то есть скоро- 
стные суда дают больший вклад в метрику. Так выявляются участки акватории с наибольшей скоростью. Третья аналогична второй, но «вес» судна зависит от его длины: более длинные суда имеют больший вес. Метрика выявляет участки акватории, где движутся самые большие суда. Похожие метрики, связанные с интенсивностью движения, рассматриваются и в других исследованиях [23; 24]. Следует отметить, что интенсивность движения и опасность связаны неявно, косвенно. Трафик может быть интенсивным, но безопасным; разреженным, но опасным.

В работах [6; 9] обосновывается метрика «стабильность параметров движения», которая характеризует вариативность скоростей и курсов. Она позволяет выявлять участки акватории со стабильным или нерегулярным, «хаотичным» движением. В статьях [7; 9] предложена метрика «насыщенность трафика», характеризующая плотность находящихся на участке акватории судов с точки зрения их возможности совершать манёвры. Она оценивает потенциальную опасность трафика, которая может обернуться в реальные опасные ситуации при неблагоприятном стечении обстоятельств, формализует эмоциональную нагрузку на участников движения. Возможна интегрированная комплексная оценка безопасности движения на акватории [9], получаемая по результатам вычисления нескольких метрик.

В качестве примера использования обсуждаемых результатов моделирования для планирования безопасных схем движения судов рассмотрим схему судопотоков на рис. 5 a.
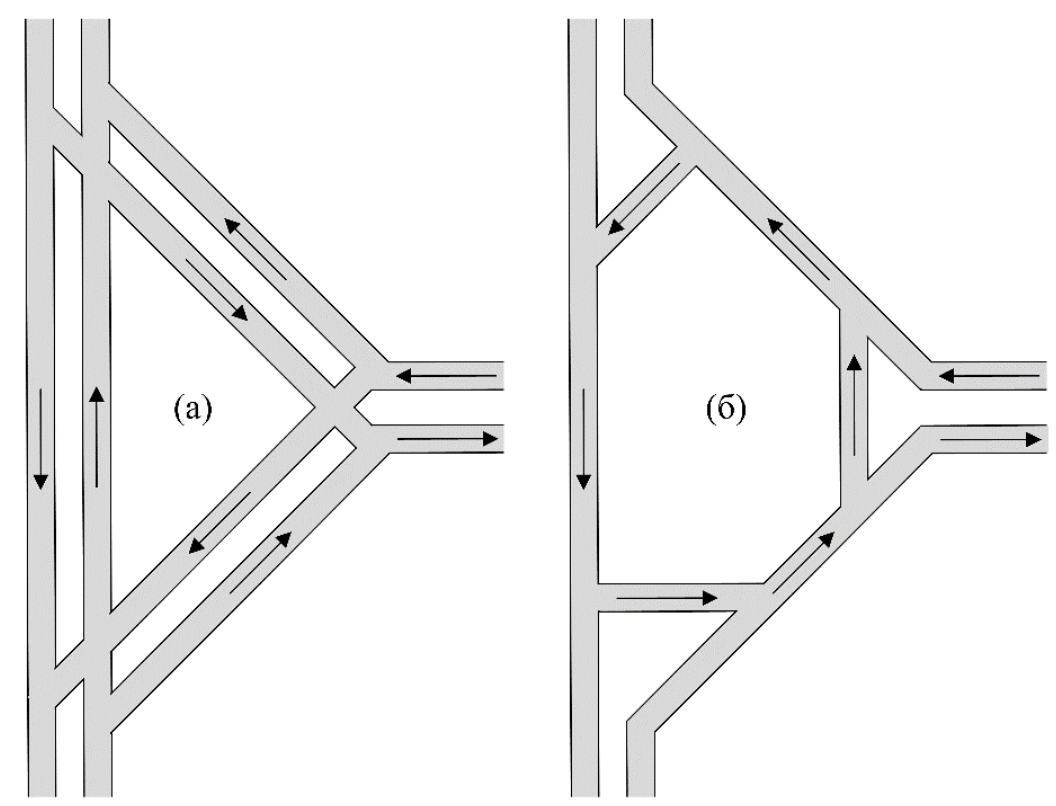

Рис. 5. Варианты схем движения судов

Здесь имеется двустороннее движение судов в направлениях «север-юг», «север-восток» и «юг-восток» таким образом, что образуется фигура, похожая 
на треугольник. Такой элемент трафика встречается на акваториях довольно часто: например, он присутствует у схемы движения судов в заливе Находка. В варианте рис. 5а имеется 6 пересечений односторонних судопотоков: по два пересечения под углами 45,135 и $90^{\circ}$. Если обратиться к данным графиков рис. 2 и 3 , то можно определить, что, например, при $R^{*}=300$ метров и случайном интервале времени между судами в отрезке $[1,10]$ минут будем иметь значение $\tau=2.85$ мин, которое относится к опасному диапазону.

Заменим схему рис. 5а на эквивалентную ей по связности схему рис. 56 (похожую на круговое движение). В ней имеем всего 3 пересечения односторонних судопотоков под углом $45^{\circ}$, что даёт значение $\tau=8.33$ мин, которое относится к безопасному диапазону. Пропускная способность схемы рис. 5б оказывается почти в три раза выше. Разумеется, речь идёт об идеальном случае, для вывода об опасности и пропускной способности конкретной схемы движения реальной акватории потребуется провести более ёмкое моделирование. Тем не менее, рассматриваемый в настоящей работе подход, основанный на использовании данных моделирования движения на примитивах, даёт вполне информативные результаты.

\section{Заключение}

В работе рассматривается задача планирования схемы движения судов, обеспечивающей безопасность трафика морской акватории. Сформулированы общие модельные представления задачи, отмечается, что перебор возможных маршрутов судов (в том числе, с использованием различных эвристик) не даёт возможности адекватно оценить меру их безопасности. В качестве альтернативы предлагается конструирование возможных схем движения экспертным способом из типичных конфигураций траекторий (примитивов).

Предложены четыре модели примитивов траекторий судов: пересечение односторонних судопотоков одинаковой интенсивности, двусторонних судопотоков одинаковой интенсивности, двусторонних судопотоков разной интенсивности и двусторонних судопотоков с зоной кругового движения. Отмечается, что такие структурные элементы траекторий судов широко распространены в судоводительской практике.

Результаты статистического моделирования движения судов по траекториям выбранных примитивов дают представление о характерном числе опасных сближений при тех или иных характеристиках судопотока. С учетом статистического характера задачи в качестве величины, характеризующей опасность того или иного примитива траекторий судов, удобно выбрать среднее время, которое проходит между опасными сближениями. Возможны и другие меры оценки опасности трафика. В работе приведён пример использования полученных результатов моделирования для планирования безопасных схем движения судов.

Предложенный подход позволяет достаточно информативно оценивать степень опасности схемы движения с качественной точки зрения. Однако трафик реальных акваторий характеризуется многообразием возможных маршрутов и траекторных свойств движущихся судов. Нередко на них присутствует множество судов, движение которых не носит характер устойчивых потоков (прогулочные катера и яхты, рыбопромысловые суда, плавсредства береговых служб и 
т.п.), а их движению свойственна значительная случайная компонента. В этом случае для решения задачи потребуется более ёмкое моделирование движения, возможно, с использованием специализированных программных систем, чему авторы планируют посвятить отдельное исследование.

1. Алексеев А. А. Конфигурация управляющего комплекса в вариации мультиагентной системы потока судов в концепции развития Е-навигации // Транспортное дело России. - 2020. - № 4. - С. 197-200.

2. Астреин В.В., Кондратьев С.И., Хекерт Е.В. Алгоритм самоорганизации групп судов для предупреждения столкновений // Эксплуатация морского транспорта. - 2016. № 2(79). - С. 45-50.

3. Бродский П.Г., Румянцев Ю. В., Некрасов С.Н. К вопросу оценки влияния интенсивности судоходства на аварийность // Навигация и гидрография. - 2010. - № 30.C. $36-42$.

4. Бурылин Я. В., Попов А. Н. Авторулевой безэкипажного судна // Эксплуатация морского транспорта. - 2019. - № 3 (92). - С. 41-45.

5. Гриняк В. М. Планирование маршрутов судов на основе кластеризации ретроспективных данных трафика акватории // Территория новых возможностей. Вестник Владивостокского государственного университета экономики и сервиса. -2021 . - Т. 13, № 2. C. 61-78.

6. Гриняк В.М., Девятисильный А.С., Иваненко Ю.С. Поддержка принятия решений при обеспечении безопасности движения судов на основе кластеризации траекторий // Вестник государственного университета морского и речного флота им. адмирала С.О. Макарова. - 2020. - Т. 12, № 3. - С. 436-449.

7. Гриняк В.М., Девятисильный А.С., Шуленина А. В. Оценка опасности схемы движения на акватории мерой нагрузки на судоводителей // Транспорт: наука, техника, управление: научный информационный сборник. - 2019. - № 12. - С. 35-40.

8. Гриняк В.М., Девятисильный А.С., Люлько В.И. Оценка опасности трафика морской акватории по данным Автоматической идентификационной системы // Вестник государственного университета морского и речного флота им. адмирала С.О. Макарова. 2017. - Т. 9, № 4. - С. 681-690.

9. Цифровое представление и комплексная оценка навигационной безопасности движения на морских акваториях / В.М. Гриняк, Ю.С. Иваненко, В.И. Люлько [и др.] // Моделирование, оптимизация и информационные технологии. - 2020. - Т. 8, № 1 (28). C. $40-41$.

10. Ермаков С. В. Особенности зрительного восприятия навигационной информации в бухтах с холмистым рельефом побережья и их влияние на безопасность плавания // Вестник государственного университета морского и речного флота им. адмирала С. О. Макарова. - 2018. - Т. 10, № 5. - С. 911-921.

11. Кирсанов М. Н. Анализ алгоритмов выбора оптимальных маршрутов группы судов // Вестник государственного университета морского и речного флота им. адмирала С.О. Макарова. - 2016. - № 2. - С. 183-190.

12. Лентарёв А.А. Основы теории судопотоков. - Владивосток: Интермор, 1995. - 76 с.

13. Лентарёв А. А. Проблемы организации движения судов в дальневосточных водах // Транспортное дело России. - 2015. - № 6. - С. 256-257.

14. Малыгин И. Г., Комашинский В. И., Королев О. А. Информационно-управляющие системы водного транспорта в период четвертой индустриальной революции // Транспорт: наука, техника, управление: научный информационный сборник. 2017. - № 8. - C. 3-12.

144 
15. Матвеев А. А., Кузнецов В.Н., Гаскаров В. Д. Обзор технических средств и методов спутниковой навигации судов // Вестник государственного университета морского и речного флота им. адмирала С.О. Макарова. - 2016. - № 1 (35). - С. 207-214.

16. Некрасов С.Н., Леденёв Н.И. Комплексный ситуационный подход к оценке навигационной безопасности плавания // Навигация и гидрография. - 2019. - № 55. - С. 34-42.

17. Попов А.Н. Безопасное маневрирование более чем одного судна при входе на фарватер порта, в узкости и условиях малочисленного экипажа в концепции развития Е-навигации // Эксплуатация морского транспорта. - 2019. - № 4 (93). - С. 27-32.

18. Таратынов В.В. Целесообразность разделения морских путей // Морской флот. - 1969. № 9. - C. 19-20.

19. Таратынов В. П. Судовождение в стесненных районах. - Москва: Транспорт, 1980.$128 \mathrm{c}$.

20. Системы управления безэкипажными судами / А. В. Титов, Л. Баракат, В. А. Чанчиков [и др.] // Морские интеллектуальные технологии. - 2019. - № 1-4 (43). - С. 109120.

21. Титов А., Баракат Л., Хаизаран А. Состояние и перспективы реализации технологии Е-навигации // Вестник государственного университета морского и речного флота им. адмирала С. О. Макарова. - 2019. - Т. 11, № 4. - С. 621-630.

22. Tam Ch. K., Bucknall R., Greig A. Review of collision avoidance and path planning methods for ships in close range encounters // Journal of Navigation. - 2009. - Vol. 62, Is. 3. P. 455-476.

23. Weng J., Xue S. Ship collision frequency estimation in port fairways: a case study // Journal of Navigation. - 2015. - Vol. 68, Is. 03. - P. 602-618.

24. Mapping global shipping density from AIS data / L. Wu, Y. Xu, Q. Wang, F. Wang, Zh. Xu // Journal of Navigation. - 2016. - Vol. 70, Is. 01. - P. 67-81.

\section{References}

1. Alekseev A. A. Konfiguraciya upravlyayushchego kompleksa v variacii mul'tiagentnoj sistemy potoka sudov v koncepcii razvitiya E-navigacii // Transportnoe delo Rossii. - 2020. № 4. - S. 197-200.

2. Astrein V.V., Kondrat'ev S.I., Hekert E.V. Algoritm samoorganizacii grupp sudov dlya preduprezhdeniya stolknovenij // Ekspluataciya morskogo transporta. - 2016. - № 2(79). S. $45-50$.

3. Brodskij P.G., Rumyancev Yu. V., Nekrasov S.N. K voprosu ocenki vliyaniya intensivnosti sudohodstva na avarijnost' // Navigaciya i gidrografiya. - 2010. - № 30. - S. 36-42.

4. Burylin Ya. V., Popov A. N. Avtorulevoj bezekipazhnogo sudna // Ekspluataciya morskogo transporta. - 2019. - № 3 (92). - S. 41-45.

5. Grinyak V. M. Planirovanie marshrutov sudov na osnove klasterizacii retrospektivnyh dannyh trafika akvatorii // Territoriya novyh vozmozhnostej. Vestnik Vladivo-stokskogo gosudarstvennogo universiteta ekonomiki i servisa. - 2021. - T. 13, № 2. - S. 61-78.

6. Grinyak V.M., Devyatisil'nyj A.S., Ivanenko Yu.S. Podderzhka prinyatiya reshenij pri obespechenii bezopasnosti dvizheniya sudov na osnove klasterizacii traektorij // Vestnik gosudarstvennogo universiteta morskogo i rechnogo flota im. admirala S.O. Makarova. 2020. - T. 12, № 3. - S. 436-449.

7. Grinyak V.M., Devyatisil'nyj A. S., Shulenina A. V. Ocenka opasnosti skhemy dvizhe-niya na akvatorii meroj nagruzki na sudovoditelej // Transport: nauka, tekhnika, upravlenie: nauchnyj informacionnyj sbornik. - 2019. - № 12. - S. 35-40. 
8. Grinyak V.M., Devyatisil'nyj A.S., Lyul'ko V.I. Ocenka opasnosti trafika morskoj akvatorii po dannym Avtomaticheskoj identifikacionnoj sistemy // Vestnik gosu-darstvennogo universiteta morskogo i rechnogo flota im. admirala S. O. Makarova. - 2017. - T. 9, № 4. S. 681-690.

9. Cifrovoe predstavlenie i kompleksnaya ocenka navigacionnoj bezopasnosti dvizheniya na morskih akvatoriyah / V. M. Grinyak, Yu. S. Ivanenko, V. I. Lyul'ko [i dr.] // Modelirovanie, optimizaciya i informacionnye tekhnologii. - 2020. - T. 8, № 1 (28). - S. 40-41.

10. Ermakov S. V. Osobennosti zritel'nogo vospriyatiya navigacionnoj informacii v buhtah s holmistym rel'efom poberezh'ya i ih vliyanie na bezopasnost' plavaniya // Vestnik gosudarstvennogo universiteta morskogo i rechnogo flota im. admirala S. O. Makarova. 2018. - T. 10, № 5. - S. 911-921.

11. Kirsanov M.N. Analiz algoritmov vybora optimal'nyh marshrutov gruppy sudov // Vestnik gosudarstvennogo universiteta morskogo i rechnogo flota im. admirala S. O. Makarova. 2016. - № 2. - S. 183-190.

12. Lentaryov A. A. Osnovy teorii sudopotokov. - Vladivostok: Intermor, 1995. - $76 \mathrm{~s}$.

13. Lentaryov A. A. Problemy organizacii dvizheniya sudov v dal'nevostochnyh vodah // Transportnoe delo Rossii. - 2015. - № 6. - S. 256-257.

14. Malygin I. G., Komashinskij V.I., Korolev O. A. Informacionno-upravlyayushchie sistemy vodnogo transporta $\mathrm{v}$ period chetvertoj industrial'noj revolyucii // Transport: nauka, tekhnika, upravlenie: nauchnyj informacionnyj sbornik. - 2017. - № 8. - S. 3-12.

15. Matveev A. A., Kuznecov V. N., Gaskarov V. D. Obzor tekhnicheskih sredstv i metodov sputnikovoj navigacii sudov // Vestnik gosudarstvennogo universiteta morskogo i rechnogo flota im. admirala S.O. Makarova. - 2016. - № 1 (35). - S. 207-214.

16. Nekrasov S. N., Ledenyov N. I. Kompleksnyj situacionnyj podhod k ocenke navigacionnoj bezopasnosti plavaniya // Navigaciya i gidrografiya. - 2019. - № 55. - S. 34-42.

17. Popov A. N. Bezopasnoe manevrirovanie bolee chem odnogo sudna pri vhode na farvater porta, v uzkosti i usloviyah malochislennogo ekipazha v koncepcii razvitiya E-navigacii // Ekspluataciya morskogo transporta. - 2019. - № 4 (93). - S. 27-32.

18. Taratynov V. V. Celesoobraznost' razdeleniya morskih putej // Morskoj flot. - 1969. № 9. - S. 19-20.

19. Taratynov V.P. Sudovozhdenie v stesnennyh rajonah. - Moskva: Transport, 1980 - $128 \mathrm{~s}$.

20. Sistemy upravleniya bezekipazhnymi sudami / A.V. Titov, L. Barakat, V.A. Chanchikov [i dr.] // Morskie intellektual'nye tekhnologii. - 2019. - № 1-4 (43). - S. 109-120.

21. Titov A., Barakat L., Haizaran A. Sostoyanie i perspektivy realizacii tekhnologii E-navigacii // Vestnik gosudarstvennogo universiteta morskogo i rechnogo flota im. admirala S.O. Makarova. - 2019. - T. 11, № 4. - S. 621-630.

(C) В.М. Гриняк, 2021

Для цитирования: Гриняк В. М. Планирование схемы безопасного движения на морской акватории // Территория новых возможностей. Вестник Владивостокского государственного университета экономики и сервиса. - 2021. - Т. 13, № 3. - С. 132-146.

For citation: Grinyak V.M. Planning of safe traffic schema for marine area, The Territory of New Opportunities. The Herald of Vladivostok State University of Economics and Service, 2021, Vol. 13, № 3, pp. 132-146.

DOI https://doi.org/10.24866/VVSU/2073-3984/2021-3/132-146

Дата поступления: 17.08.2021.

146 